\title{
OBLIQUE IMAGES AND DIRECT PHOTOGRAMMETRY WITH A FIXED WING PLATFORM: FIRST TEST AND RESULTS IN HIERAPOLIS OF PHRYGIA (TK)
}

\author{
G. Sammartano ${ }^{1 *}$, F. Chiabrando ${ }^{1}$, A. Spanò ${ }^{1}$ \\ ${ }^{1}$ Department of Architecture and Design (DAD) - Politecnico di Torino, Viale Mattioli 39, 10125 Torino (Italy) \\ giulia.sammartano@polito.it; filiberto.chiabrando@polito.it; antonia.spanò@polito.it
}

Commission II, ICWG I/II

KEY WORDS: UAV, direct photogrammetry, DSM, PPK, RTK, archaeology mapping, data integration

\begin{abstract}
:
The complex archaeological site documentation benefits for a long time now from the aerial point of view and remote sensing methods. Moreover, the recent research on UAV photogrammetry platform equipment and flight planning actively contribute in this sense for a scaling improvement and cost-benefits balance. Frequently, the experiences on articulated topographic profiles in archaeological excavations require not only a multi-sensor approach but also and above all a multiscale one. According to this line, in a general time-cost ration framework, the geometric content of the generated DSMs should be complete of nadir and oblique point of view for the accurate $3 \mathrm{D}$ reconstruction of both upstanding buildings and excavations. In the same way, also the radiometric content closely depends on sensor payload quality and is strictly affected by excavation site condition, related to the site material and light. In this research, carried out in the impressive archaeological site of the ancient city of Hierapolis in Phrygia (Turkey) in the autumn 2019 campaign, the main goal was to evaluate and validate the overall performance of a novel UAV fix-wing ultralight platform with onboard GNSS receiver for RTK/PPK processing of cameras positioning and with the possibility of oblique images capturing. The expected contribute in terms of the acquisition, processing time, radiometric enhancement and geometry 3D reconstruction will be explored with preliminary test and outcomes, and with the results of the high-scale DSM and orthoimage generation of the complete Hierapolis site.
\end{abstract}

\section{INTRODUCTION}

In the context of wide range and high scale mapping, especially in complex archaeological documentation domain, we are recently witnessing the evolution of advanced and adaptive technological solutions for photogrammetric purposes and digital 3D modelling with the use of Unmanned Aerial Vehicles (UAV) equipment. They allow more and more the integration and improvements of sensors payloads as camera models variability and GNSS receivers types. Indeed, this positively contributes to the methodology performance not only in operational conditions in terms of time-cost ration but also in the sense of improving metric results richness as well as the accuracy control. The two main key issues faced in this research are related to the optimization of the methodological processes supporting the drone survey that dealing with the image acquisition and the topographic measurements phases. For these reasons, drones are increasingly developed with accurate onboard GNSS receivers for more precise real-time positioning aimed at direct photogrammetry solution (Chiabrando, Giulio Tonolo, \& Lingua, 2019) and with high-quality sensors and experimenting tilting cameras (Amrullah, Suwardhi, \& Meilano, 2016). Specifically, the fixed wing eBeeX by Sensefly is presented and explored in this research in an outstanding context: the Hierapolis ancient city in Turkey. The preliminary tests on the platform regard its new potential in 3D mapping workflows steps, due to the tilted camera for oblique imaging and the RTK/PPK GNSS positioning. These innovations allow to deploy continuous and multi-temporal documentation strategies not only for punctual $3 \mathrm{D}$ reconstruction purpose but for planning monitoring and updating survey campaigns. These approaches can be extremely advantageous in extensive archaeological contexts, where a multi-sensor approach for multiscale documentation is typically required. As it is well known, in many application UAV photogrammetry is not an independent method, and it is frequently flanked by a multi-sensor approach in such kink of extended sites, usually requiring multiscale data and concerning multi-purposes uses (Chiabrando, Spanò, Sammartano, \& Teppati Losè, 2017; Guidi et al., 2009; Remondino et al., 2009).

\subsection{UAV photogrammetric approach for extended 3D} mapping and complex topographic sites

The adoption of photogrammetric pipelines based on Structurefrom-Motion (SfM) and multi-view stereo (MVS) algorithms, using images acquired by UAVs is nowadays widely well recognized as a winning approach in an efficient extensive $3 \mathrm{D}$ mapping (Colomina \& Molina, 2014; Nex \& Remondino, 2014). Technological advances on unmanned platforms exploiting onboard positioning and imaging sensors, parallel to lowering production and distribution costs, as well as processing Computer Vision (CV) algorithms proficiency, make it now a flexible and efficient method, especially in extensive heritage documentation, where the complexity and content richness of the 3D scene reconstruction is a key-topic (Murtiyoso \& Grussenmeyer, 2017). Particularly for archaeology domain, the research on the closerange aerial point of view has been a crucial turning point (Nikolakopoulos, Soura, Koukouvelas, \& Argyropoulos, 2017). Starting from many experiences using light, developed with various UAV rotors configuration and equipment (Campana, 2017; Sauerbier \& Eisenbeiß, 2010; Themistocleous, 2014). Here, the primary purposes in the generation of UAV-based models is usually the quick availability of $3 \mathrm{D}$ data complete, accurate and georeferenced too, as DSMs and orthoimages products (Campana, 2017) to derive metric information, mutitemporal and multi-sensor too for inspection and monitoring. Although it can be assumed that the UAV photogrammetric method has been quite profoundly investigated in last two

\footnotetext{
* Corresponding author
} 
decades, and it has been verified the capability to meet the scaledetail needs of the archaeology domain from low scale mapping up to very close-range scale, it is likewise possible to affirm that many open issues still need to be addressed in current research. In this scenario, hot topics in the direction of both optimizations for images positioning accuracy and maximization of geometric reconstruction of $3 \mathrm{D}$ objects with emphasized verticality should be taken into high consideration. They can be synthetically grouped according to:

1) onboard sensors for direct georeferencing

2) flight plan pattern and overlapping

3) camera configuration

If in the first case, the outcomes of an accurate direct georeferencing successfully contribute to speed up the topographic acquisition time (Ekaso, Nex, \& Kerle, 2020; Harwin \& Lucieer, 2012), usually weighed down by support of ground-based measurements techniques, the other two aspects are more related to the robustness in block adjustment and to the maximization of richness and continuity in $3 \mathrm{D}$ reconstruction results, ensuring dense image-matching and avoiding data gaps. The use of high-performance on-board sensors such as GNSS or IMU platform is a significant research issue that is continuously under development. Mainly in the last years, the research was focused on the improvement of the performance of the on-board GNSS since the most critical components in the Bundle Block Adjustment is related to the position of the images. The attitude could improve the final results, but the accuracy is not crucial like the component associated with the correct evaluation of the poses (Kraus, K., Jansa, J., \& Kager, 1997). For this reason, different platforms equipped with high-performance onboard GNSS have been developed by the leading UAV companies. These systems are mainly able to manage the estimation and recording of the position in different ways: 1) acquire data and storing the GNSS information for performing a PPK (Post Processing Kinematik) processing, 2) following an RTK (Real Time Kinematik) approach where the onboard GNSS is connected with a GNSS master station (positioned on a known point) via radio-link, 3) with a RTK approach combining with a GNSS Networked Transport of RTCM via Internet Protocol (NTRIP) for an NRTK approach. For sure the use of this opportunity open a new era in the use of UAV for mapping purpose since the ambition is related to the removal of the GCPs acquisition on the field that is without any doubt very time spending.

Furthermore, the combination of strips with a high level of overlapping areas and the combination of orthogonal blocks in case of extensive mapping in addition to, if required, circular paths around the object, allows boosting local and global accuracy and minimizing the use of ground control points distribution (Teppati Losè, 2019).

The expected benefits from oblique poses integration are generally well confirmed by research on the topics both for accentuated 3D surfaces and approximately-planar areas (Meinen \& Robinson, 2020; Verykokou \& Ioannidis, 2018). Nevertheless, the crucial aspect to be taken into consideration in the flight plan with oblique cameras is a dual contribution. The use of tilting cameras mounted on UAVs not only improve the $3 \mathrm{D}$ reconstruction for higher completeness in images overlapping on the object and ensure the continuity in the densification result avoiding lake of information in elevation. Indeed, the use of oblique images blocks combined with accurately planned flight lines configurations improves the accuracy content in the metric control of 3D surfaces with high-relief.

On the other hand, however, the use of oblique pose images carries out crucial metric fallout in the inhomogeneity of GSD estimation on the ground (Lingua, Noardo, Spanò, Sanna, \& Matrone, 2017). Negative effects on the densification points distribution, delivering noise errors in foreshortened images areas (Amrullah et al., 2016), along with georeferencing approach issues could appear in the final results (Verykokou \& Ioannidis, 2018).

The well-established use of oblique cameras has been largely tested, for examples in case of complex high-relief topographic sites (Nesbit \& Hugenholtz, 2019) with a deep difference in levels (Casella \& Franzini, 2016), and within heritage site with accentuated Z-values object and architectural-scale requirements. For these reasons, the contribute of oblique point of view factor in UAV mapping for archaeological site documentation, and upstanding masonry structures is a challenging topic to be explored. This aspect is important both in the methodological issues and in the contest-related application, mainly due to crucial constraints condition that typically affects extensive archaeological sites survey.

Wide scenarios, as the Hierapolis ancient city of almost $3 \mathrm{~km}^{2}$, where is conducted the present research, are subject to many variables affecting first of all the acquisition phase, and then the data processing and expected results:

a) the area extension and accessibility

b) the micro- and macro-topography features

c) the environment conditions (light, colours, material, etc.)

As a solution, the benefits from the use of fixed-wing platforms, which guarantee durability, speed, wideness and regularity of the photogrammetric coverage, can be well combined with the geometric reconstruction capabilities potential of the oblique images, which instead are typically associate to multi-rotor platforms with tilt angle cameras. In fact, in this research the use of an advanced fixwing-type drone with light-weight, capable of time endurance, has been tested in an extensive archaeological site (see Par. 2), thanks to the implementation of a high-resolution tilting camera capable of triple image acquisition in nadir and oblique configuration.

\section{THE HIERAPOLIS MISSION EXPERIENCE}

The exceptional archeologic context of Hierapolis of Phrygia (Turkey), has been from a long time the opportunity where a continuous and advanced metric documentation project has been underway by MAIER (Italian Archaeological Mission) and Geomatics group from Politecnico di Torino. The multiscale documentation objectives that have been pursued on the site for many years have different directions. First, the documentation of individual monumental and architectural complexes must target the archaeological scale reading of the excavation and architectural detail of the buildings, as the excavation is often directly focused to the internal areas of the architectural complexes. The documentation requirements at this scale have been met using UAV photogrammetry with different multi-rotors devices and sensors (oblique and nadir acquisitions) as in (Spanò, Chiabrando, Sammartano, \& Teppati Losè, 2018). The very low aerial multi-rotors flights and resulting image-based models have been developed for higher scales and flanking other terrestrial and close-range mapping techniques (ranging and imaging approaches) for exploiting integration-driven purposes. An intermediate reading scale was identified to link the individual monumental complexes of the city to the surrounding environmental and natural context. In the past, it was already addressed using a GIS-based atlas of the city produced on consolidated survey techniques (topographic database of the ancient heritage and modern configuration of the site with the distribution of access routes to individual archaeological areas, to the museum, to services for tourists etc. (D'Andria, F., Scardozzi, G., Spanò, 2008). For this purpose in 2015 , a survey campaign was started from the earlier model of Sense Fly UAV (nadir images only) as in (Chiabrando, D'Andria, Sammartano, \& Spanò, 2018). In addition, the lower scale was still necessary within the multi-scale documentation approach. In fact, it was urgent the documentation of the whole ancient city and its current 
characteristics of an archaeological site subject to considerable tourist pressure, as a member of the WHL (World Heritage List) for several years, and above all, to be able to document in detail the strong links that bind this city to the natural environment, from antiquity to today.

Since the first centuries of development, Hierapolis was famous for its thermal springs, and the calcium carbonate derived from waters formed during the centuries the spectacle of limestone concretions hill that is a unique phenomenon in the world, of particular appeal, and above all under careful observation for its conservation. Hieraoplis is also considered a sacred city, both in pagan times and in the Christian ones. During the first period, according to the ancients, the entrance to the underworld was located in Hierapolis. Furthermore in Christian times, the city was the destination of pilgrimages from all over the Mediterranean due to the presence of the relics of St. Philip. Nonetheless, it was also a city devastated by multiple earthquakes, also due to a fault that runs parallel to the main road axis of the city.

These indivisible natural characters, water, limestone concretions and earthquakes, are now presented to the public and therefore had to be documented in a set of metric mapping that placed a complete DSM at the centre of the objectives at a scale between 1: 500 and 1: 1000. These are the reason why in October 2019, a complete 3D mapping by UAV survey on the whole ancient city and surroundings, using the eBee $\mathrm{X}$ mounting the S.O.D.A $3 \mathrm{D}$ tilt camera, was pursued. Figure 1



(a)

Figure 1. The acquisition phase in the fieldwork at Hierapolis archaeological site during the 2019 mission

\subsection{The new fix-wing platform with tilt camera}

The hardware characteristics of the employed platform are 1.16 $\mathrm{m}$ wingspan and $1.4 \mathrm{Kg}$ weight; moreover, the UAV is equipped by a dual-frequency GNSS that could work in RTK (Real Time Kinematic) or in PPK (Post Processing Kinematic). Those different options make the drone very flexible and allow to follow the direction of the direct photogrammetry approach without the use of any GCPs (Ground Control Points) since is possible to work using the RTK configuration with a reference station on the field or using a GNSS network (if available) or, lastly, store the GNSS observation in the platform and post-process the data once the fly is completed. Both configurations were tested in Hierapolis case and reported hereafter. Another significant improvement of the eBeeX is without any doubt the new S.O.D.A. 3D camera, that allows changing orientation during flight in order to capture $\mathrm{n}^{\circ} 3$ images 2 oblique and 1 nadir along the flight path as is shown in Figure 2. This improvement from one side enables to improve the field of view and the capacity to survey semi-vertical surfaces (cliffs and partially ancient buildings featured by upstanding structures). Moreover, from a photogrammetric point of view is important for increasing the quality of the photogrammetric block (thanks to an improvement in the block constraint using the oblique acquisition). The availability of oblique data is also an added value for extracting, with a high level of detail, extensive DSM (Digital Surface Models) and 3D point clouds of the surveyed area. Lastly, the combination of the orientation of the different image is beneficial for improving the possibility of connection with terrestrial multisensor data and documentation.

An added value of the employment of this new platform is also related to the camera resolution. As is reported in the next Table 1 the improvements are clear and allow to fly with the platform at a higher elevation to improve the surveyed area with a single fly maintaining high quality image resolution.

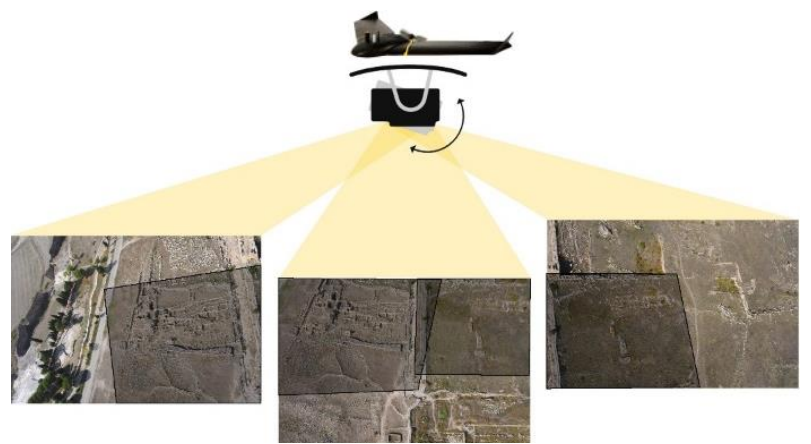

(a)

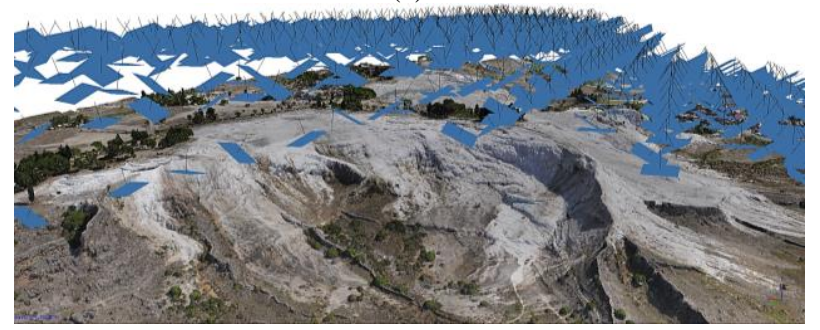

(a)

Figure 2. The images acquisition: (a) the triplet 1 nadir and 2 oblique with the overlapping area; (b) the oriented images block overlooking the limestone hill

\begin{tabular}{|l|l|l|}
\hline Camera & Canon S110 & S.O.D.A. 3D \\
\hline Acquisition & Nadir & Tilting \\
\hline Resolution & $12 \mathrm{MP}$ & $20 \mathrm{MP}$ \\
\hline Sensor size & $7.44 \times 5.58 \mathrm{~mm}$ & $13.2 \times 8.8 \mathrm{~mm}$ \\
\hline Sensor resolution & $4048 \times 3048 \mathrm{px}$ & $5472 \times 3648 \mathrm{px}$ \\
\hline Focal length & $5.2 \mathrm{~mm}$ & $10.6 \mathrm{~mm}$ \\
\hline $\begin{array}{l}\text { Expected GSD } \\
\text { @ 100m elev. }\end{array}$ & $0.04 \mathrm{~cm}$ & $0.22 \mathrm{~cm}$ \\
\hline $\begin{array}{l}\text { Expected coverage } \\
@ 100 \mathrm{~m} \text { elev. }\end{array}$ & $0.15 \mathrm{~km} 2$ & $0.1 \mathrm{~km} 2$ \\
\hline
\end{tabular}

Table 1. Comparison between Canon S 110 used during the 2015 survey campaign and the S.O.D.A 3D.

\section{TESTING THE PLATFORM POTENTIAL IN HIERAPOLIS WITH DIRECT PHOTOGRAMMETRY}

The presented research wants to preliminary explore the capabilities of this novel fix wing platform with PPK positioning solution, in the overall balance of the workflow for UAV mapping in an extended and topographically complex terrain and archaeological landscape. The final metric product is represented by the large scale accurate 3D mapping of the whole ancient city related to the exciting environment of limestone cliffs, with the 
ability to get at least a 1:500 scale detail. Thus, the boundary conditions of these survey campaign, and the criticality of the context wideness for the times and ways of accessing to the excavation spaces, are not to be underestimated. In fact, the topographic characterization of the site Figure 3 was one of the most challenging circumstances to the fulfilment of the primary goal. The North-South elevation difference is about $100 \mathrm{~m}$ instead, the West-East difference reaches a value of $200 \mathrm{~m}$ difference in level. The difference in level between measured topographic point is $80 \mathrm{~m} \mathrm{E}-\mathrm{W}$ and $40 \mathrm{~m} \mathrm{~N}$-S. In order to test the capabilities of the platform flights, a complete dataset of images, subdivided into $\mathrm{n}^{\circ} 4$ images blocks (Figure 4 ), has been acquired during $\mathrm{n}^{\circ} 1$ fieldwork day. For each dataset, different GNSS acquisitions are available.

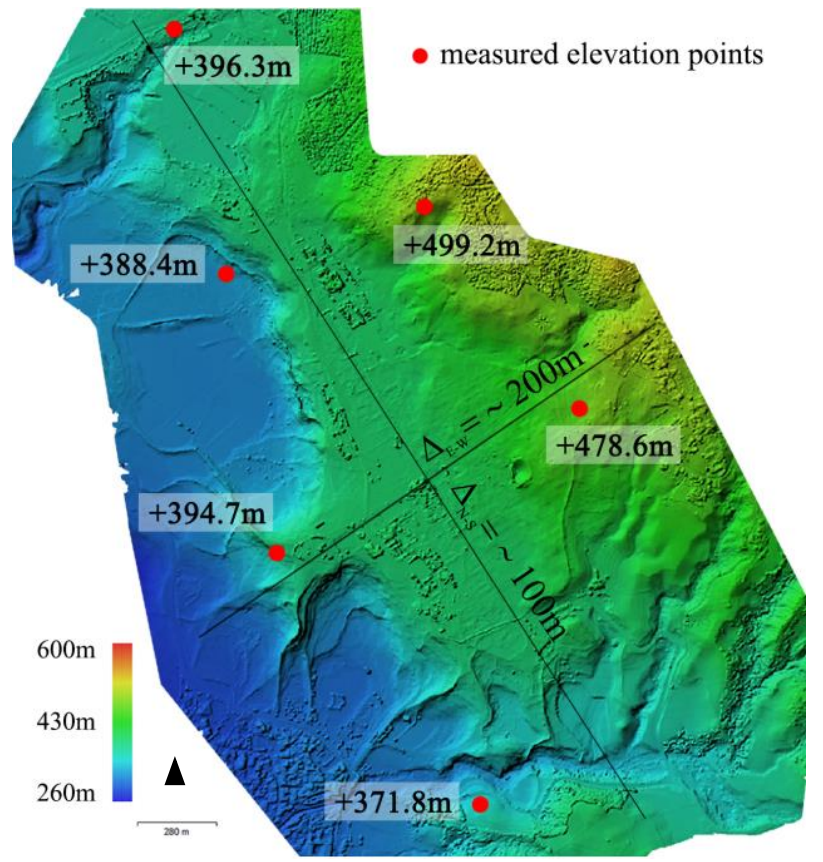

(a)



(b)

Figure 3. (a) The morphological characterization of the site with large differences in height towards the limestone hill, according the two main longitudinal and transverse section, reported in

(b).
The raw RTK position: in this case, the position of each camera during the flights (embedded in the image EXIF) is related to a GNSS reference position fixed on-the fly used during the image acquisition. Furthermore, in a first post-processing test, the reference station position was corrected thanks to the already available coordinate (these are related to the result of the main topographic network of Hierapolis). Finally, the PPK approach was followed in order to re-estimate all the camera pose. The post-processing phases has been conducted with the eMotion software interface.

Specifically, first of all, the BBA was performed following the traditional approach, that is related to the use of the measured GCPs positioned on the ground. Then, the RTK information (raw and post-processed) that allow giving the correct position of each image according to real-time correction where exploited. Finally the same process was achieved using the PPK data without the use of GCPs and using a small set of them. The different results are evaluated and reported with a comparison of the obtained accuracy using each strategy in order to understand which approach is the most suitable in terms of accuracy and time spent for data acquisition and processing. More broadly, the quality of the collected datasets will be estimated in next paragraphs, regarding the achievable accuracy both on the bundle block adjustment (BBA) (Par.3.2-.3.3) and in the 3D geometry reconstruction (Par.4), where the contribution of oblique cameras in the 3D mapping will be preliminarily evaluated.

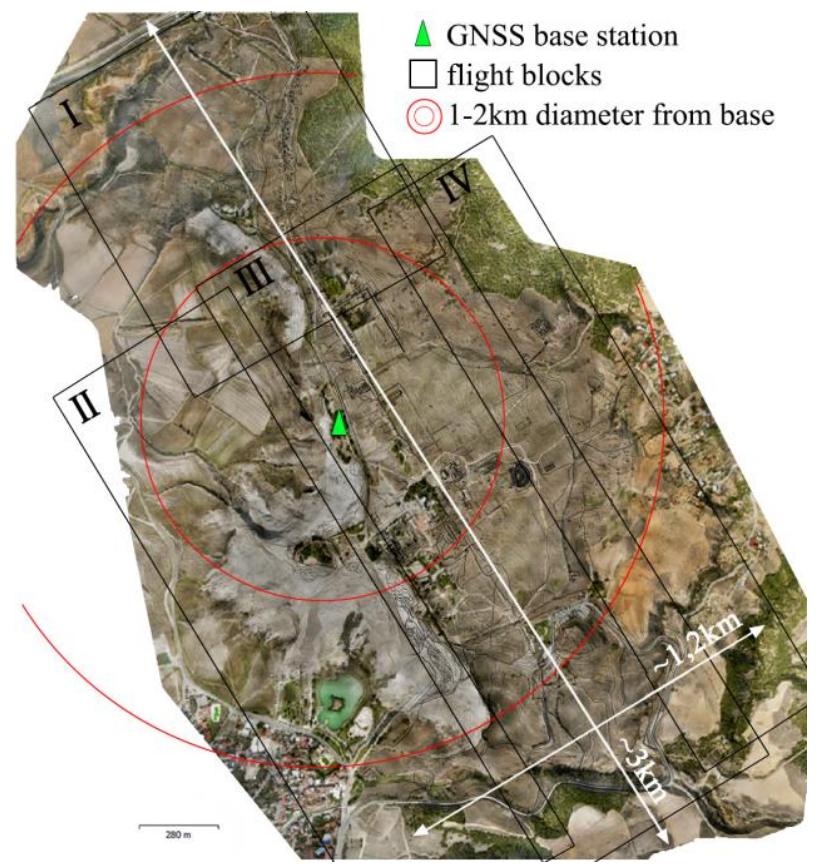

Figure 4. The resulting orthoimage of the site with indication of: the 4 flight blocks; the main extension dimensions and the GNNS base station position used for RTK/PPK positioning and its range of up to $1 \mathrm{~km}$.

\subsection{The flights planning and on-site data acquisition}

The flight planning was managed with the eMotion software interface connected with the platform system. In order to maintain a constant GSD (ground sample distance) for all the images along the different trajectories, the DTM available in eMotion was employed using the option Elevation data (AED). The whole area (Figure 4) of about $4 \mathrm{~km}^{2}$ was covered by four different flights. The flights were initially planned with the following purposes: a combination of nadir and low-oblique 
images $\left(30^{\circ}\right)$ with a flight elevation e of almost $120-150 \mathrm{~m}$, that would mean a GSD of $2-3 \mathrm{~cm}$, and at least $60 \%$ lateral overlapping and $85 \%$ longitudinal overlapping.

During the fieldwork execution, due to operational reasons of duration and optimization in the data collection phase, the flight altitude was increased at the expense of the GSD value. The necessity to fly only 1 day to cover the whole Hierapolis city has meant that the average flights' altitude raised to $180 \mathrm{~m}$. Thus, the correct estimation of average GCD on the nadir and oblique camera pose, according to (Lingua et al., 2017), should be quantified as a minimum and maximum GSD value, as in (Figure 5). If with the nadir configuration the average value is $\mathrm{GSD}=4 \mathrm{~cm}$, with the low-oblique camera setting and related coverage on the ground, the available ground resolution is $4 \mathrm{~cm}<\mathrm{GSD}<8.6 \mathrm{~cm}$.

Therefore, the real flight plan performed over the area was the following: a dataset that counts 3129 images (split into $\mathrm{n}^{\circ} 4$ blocks) captured from a mean flight altitude of $180 \mathrm{~m}$, with $60 \%$ sidelap and $80 \%$ endlap overlapping. During the flights, a Topcom GNSS G3 receiver was used as reference station.

The GNSS positioned on a point of the main topographic network of Hierapolis (in the city centre Figure 4) was employed as the reference station for the RTK correction during the flights. Furthermore, the acquired data were used for post-processing the flights using a PPK approach as well. At the same time, to perform accuracy assessment on different flight dataset evaluating the quality of varying positioning data, a set of almost $\mathrm{n}^{\circ} 50$ contrast markers points on the ground was distributed and measured using RTK/GNSS technique (Figure 6).

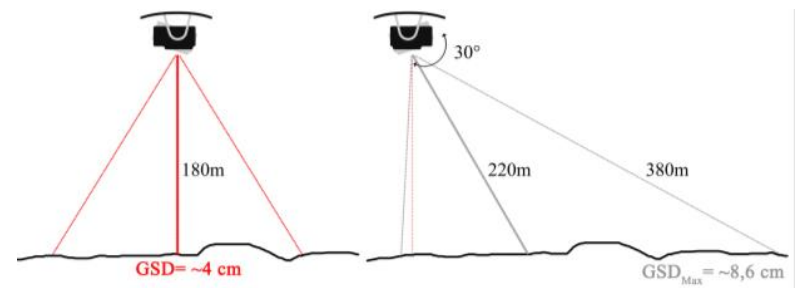

(a)

Figure 5. The estimation of average GSD on the nadir and oblique camera pose

\subsection{The datasets processing and accuracy assessment in} bundle block adjustment configuration

The main goal of the test, as introduced and it will be described in next sections, deals with the evaluation of the different strategies employed for the orientation of the photogrammetric blocks, using direct georeferencing (par. 3.4) compared to the traditional one carried out using the surveyed points (par.3.3.) as GCPs and CPs.

Starting from the acquired data, the images have been processed in parallel following the photogrammetric pipeline inside Agisoft Metashape software interface with the same parameters. The cloud processing has been exploited with $500 \mathrm{~Gb}$ storage, and the big images dataset orientation, densification and triangulation phases have been taken over by the Agisoft machines with the following hardware configurations: CPU: 32 vCPU $(2.7 \mathrm{GHz}$ Intel Xeon E5 2686 v4); GPU:2 x NVIDIA Tesla M60; RAM: 240 GB. Alignment time: $2 \mathrm{~h} 35 \mathrm{~min}$; densification process, with $40 \mathrm{pts} / \mathrm{m}^{2}$ : 8 h $16 \mathrm{~min}$; 3D model triangulation with $20 \mathrm{mln}$ triangles: $12 \mathrm{~min}$; DSM generation: $8 \mathrm{~min}$; orthoimage generation: 2 h 6 min.

The tests on accuracy assessment for the images blocks orientation were conducted using a wide points set configuration (Figure 6), in the form of GCPs-CPs for traditional processing and CPs for the validation of blocks following a direct photogrammetric approach.
The validation steps are based on the 4 different datasets, previously introduced:

A. Traditional, is the use of images block without adoption of direct positioning and with bundle block adjustment based on GCPs. The test is the [1].

B. RTKraw, is the use of images block with the position of the GNSS reference station employed for the RTK correction fixed on-the-fly. The test is the [2].

C. RTKcorrect, is the images dataset B after the correction of the coordinate of the GNSS base station. In this case, the RTK is post-processed in eMotion using the accurate coordinate of the base station (that could be evaluated using a PPP approach or in a traditional topographic network). After this process the image geotag positions is updated according to the new base station coordinates. The test is the [3].

D. $\boldsymbol{P P K}$, is the final dataset after the kinematic post-processing phase performed in eMotion with the data acquired from the base station and the onboard GNSS independently. Using this configuration we follow two different approaches: test [4] proposed with only CPs use for check the quality of PPK and test [5] carried out with the use of only $n^{\circ} 3$ GCPs.

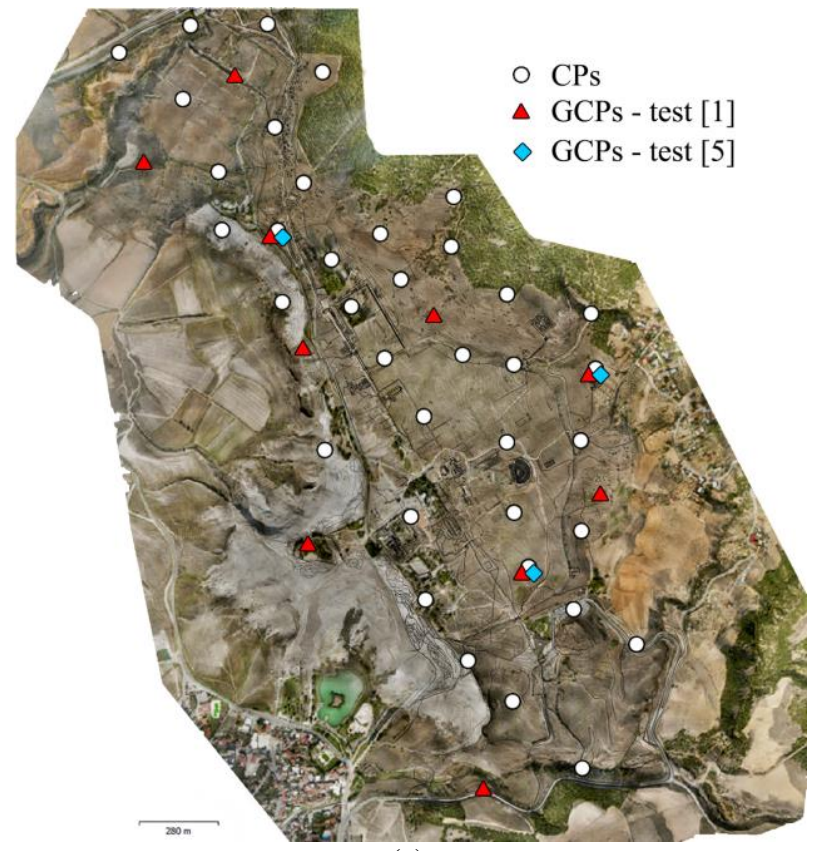

(a)

Figure 6. (a) The GCPs and CPs distribution in the test [1]standard BBA and in the test [2]-PPK camera positions.

\subsection{The accuracy assessment using GCPs}

The accuracy assessment on direct georeferencing is compared with a traditional BBA processing based on the common pipeline: image-matching and tie points extraction for cameras orientation (internal, external) camera self-calibration; absolute positioning using the identification of GCPs in the BBA optimization. The result of the standard test [1] is reported in Table 2.

A second evaluation is now required, downstream the results of Table 2 related to the complete BBA and due to the inhomogeneity of RMSE values distribution: this considers the very complex topography conformation of the site, and it tries to separate and weight the RMSE distribution according to the site areas splitting the GCPs blocks: northern, centre, southern Table 3. It is important to underline in this step the magnitude of the 
error located in the GCPs measured in the most topographically complex and distant area: the southern one. If limiting the evaluation at northern and central blocks, the accuracy assessment can be successfully considered for a high-scale mapping for 1:200-1:500 scale detail.

\begin{tabular}{l|l|cccc} 
& & $\mathrm{X}(\mathrm{m})$ & $\mathrm{Y}(\mathrm{m})$ & $\mathrm{Z}(\mathrm{m})$ & 3DError $(\mathrm{m})$ \\
\hline \multirow{2}{*}[1]{} & $\mathrm{n}^{\circ} 35 \mathrm{GCPs}$ & 0.0876 & 0.0542 & 0.0117 & 0.1036 \\
& $\mathrm{n}^{\circ} 10 \mathrm{CPs}$ & 0.1844 & 0.1227 & 0.0657 & 0.2310
\end{tabular}

Table 2. The RMSE results on GCPs and CPs for the traditional processing images block, without direct geo-referencing data.
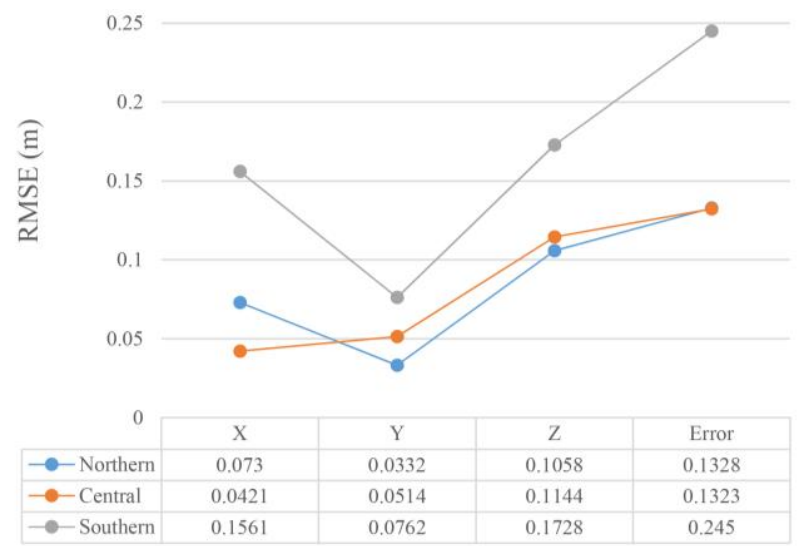

Table 3. RMSE trend on GCPs according to the spatial distribution on the site areas.

\subsection{The accuracy assessment on direct photogrammetry}

The following part of the evaluation refers to the positional accuracies of the three blocks and related tests: [2] RTK raw, [3] RTK corrected and [4] PPK. Measured points have not been used for aerial triangulation but only for accuracy check. The first considerations are reported on the RMSE estimated on the measured points used as CPs, determining hence the accuracy of the BBA. Table 4 demonstrates the increasing performance of the corrected RTK positioning data compared to the raw one. But the best result is obtained with the kinematic post-processing using the reference base station. A global error of $0.3 \mathrm{~m}$ has been obtained.

\begin{tabular}{l|l|cccc} 
& $\mathrm{n}^{\circ}$ 45 CPs & $\mathrm{X}(\mathrm{m})$ & $\mathrm{Y}(\mathrm{m})$ & $\mathrm{Z}(\mathrm{m})$ & 3D Error $(\mathrm{m})$ \\
\hline [2] & RTK raw & 0.8096 & 0.6913 & 4.7029 & 4.822 \\
[3] & RTK correct & 0.5547 & 0.4302 & 1.8079 & 1.9394 \\
[4] & PPK & 0.2246 & 0.1804 & 0.1125 & 0.3092
\end{tabular}

Table 4. Check of RMSE on CPs for the three configurations of georeferenced images blocks

In Table 5 the results on an additional test [5] regarding the use of a small set of 3GCPs involved in the BBA, allowing the possible improvement of the accuracy results and the overall PPK dataset performance.

\begin{tabular}{|l|cccc} 
PPK dataset & $\mathrm{X}(\mathrm{m})$ & $\mathrm{Y}(\mathrm{m})$ & $\mathrm{Z}(\mathrm{m})$ & Error $(\mathrm{m})$ \\
$\mathrm{n}^{\circ} \mathbf{3}$ GCPs & 0.0869 & 0.0830 & 0.0143 & 0.1210 \\
$\mathrm{n}^{\circ} 42 \mathrm{CPs}$ & 0.2143 & 0.1625 & 0.1167 & 0.2932
\end{tabular}

Table 5. Check of RMSE on bundle block adjustment for the PPK images block

These preliminary results are acceptable and suitable for the expected scale, but strictly depending from context-related factors, first of all, related to the topographic measurement quality and then connected to the flight condition over long distances and topographic irregularities for overlapping and nonomogeneity of GSD estimation. It could be stated that seriously influence the final performance evaluation, that requires further tests.

The complementary part of the test is referring to the evaluation of the camera position estimation in the different datasets using the direct photogrammetry approach with the aim of confirming or not the results derived from the evaluation performed by GCPs and CPs.

In Table 6 , the $\sigma$ values represent the errors of camera position estimation according to the three directions and for the total error vector after the alignment phase of the three datasets.



Table 6. Camera position differences between original and estimated data of each dataset, after image alignment

\begin{tabular}{c|cccc} 
& & $\sigma \mathrm{E}(\mathrm{m})$ & $\sigma \mathrm{N}(\mathrm{m})$ & $\sigma$ elev $(\mathrm{m})$ \\
\hline & Mean & 0.2404 & 0.7874 & -4.7521 \\
{$[2]-[4]$} & $\mathrm{M}$ & 0.3665 & 1.2702 & -4.5487 \\
& $\mathrm{~m}$ & 0.1595 & 0.5103 & -5.0568 \\
& St.dev & 0.0190 & 0.2919 & 0.1475
\end{tabular}

Table 7. The spatial camera position shifts between in the three directions raw GNSS geotag dataset and PPK dataset

In Table 7, the camera absolute positions is evaluated on the whole dataset, considering the difference between the original data from on-board GNSS in RTK model and the final estimation of camera position after the PPK solution. Except for the elevation shift that was expected, the differences between the positions of the cameras confirms the good evaluation performed through the usual approach that includes RMSE on GCPs and CPs.

\section{DSM GENERATION BY UAV MAPPING AND CONTRIBUTION OF OBLIQUE CAMERAS}

A final discussion is proposed to evaluate the level of accuracy in the geometric content of the 3D model derived from the eBeeX DSM, its richness and the ability to describe complex topographic landscapes. In consideration of the more effective contribution of oblique images at major scales, a test was conducted to evaluate the extent of the improvements in term of Bundle block enhancement and final richness and quality of derived 3D point cloud and DSM. The particular area featured by a very steep slope topography, in the central part along the limestone hill and the Frontino main road, has been chosen. The separate use of nadir and nadir plus oblique images configuration blocks were considered in parallel processing and DSM generation (Figure 8). Even though the test is influenced by a weak overlapping among nadir images (extracted from the complete set and not acquired from a separate planned flight), the result of a different accuracy of bundle adjustment and the 
different density of point cloud generation together with gaps presence, are not unexpected.



(a)

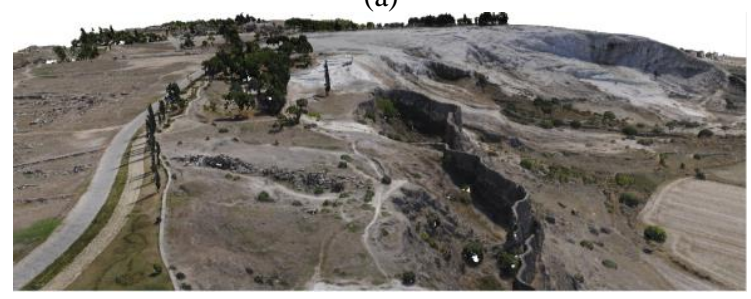

(b)

Figure 7. Two bird's-eye views of the point-based DSM over the

Hierapolis site (a) and particularly the limestone hill (b)

The Figure 8 show a visual comparison of two point clouds models: without gaps in the left, and generated with holes for lack of information during the cloud densification, in the right.

The two models were compared using a $\mathrm{C} 2 \mathrm{C}$ algorithm that provides residuals ranging to about 1 metre for the architectural structures of a certain height, as well as trees.

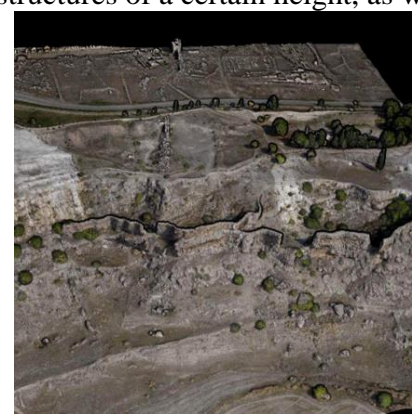

(a)

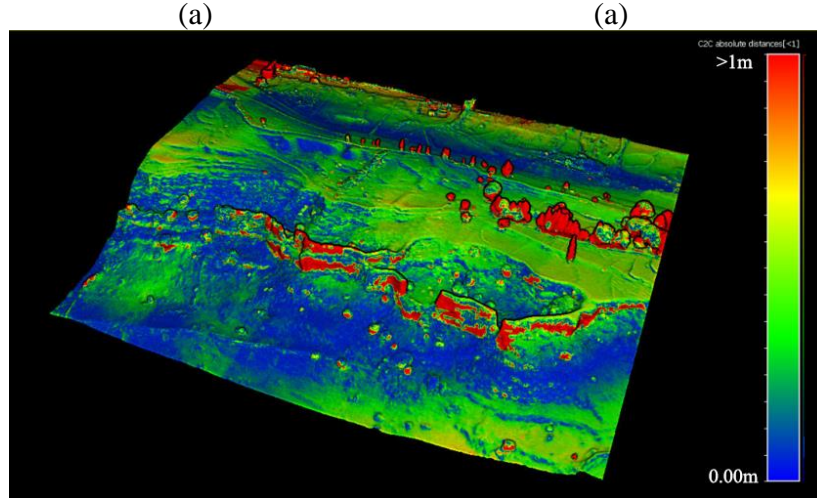

Figure 8. The comparison between the two point clouds: (a)

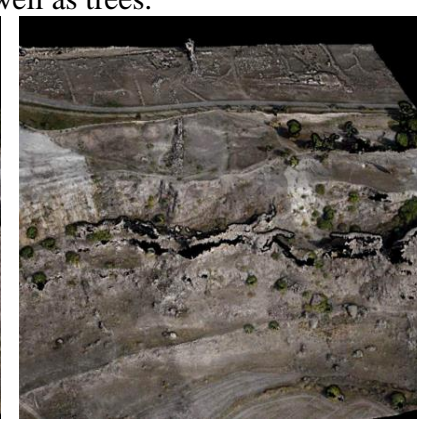

(a) nadir+oblique integration; (b) nadir-only view; (c) $\mathrm{C} 2 \mathrm{C}$ comparison map representing the difference and the contribution on oblique data.

\section{DSM GENERATON FOR LARGE-SCALE 3D MAPPING}

A perspective discussion is now proposed on the optimization of UAV mapping in complex sites and synthesized as follow in a series of consideration on operative pipeline arrangement.

As we experienced, the Hierapolis ancient city of almost $3 \mathrm{~km}^{2}$, where the present research was conducted, we encountered the variables aforementioned:

a) the area extension and accessibility profoundly influenced the survey approach and schedule of the survey mission

b) the micro and macro-topography features needed accurate flight planning and required the use of the new eBeeX platform with S.O.D.A 3D camera

c) the environment conditions (light, colours, material, etc.) were challenging condition to be faced. The digitization of the high reflectivity of the limestone hill should be balanced with the distribution of the green space around and across the large sandy terrain and impressive travertine building structures.

The joint occurrence of these conditions to be balanced and met, usually does not guarantee time savings and involvement of tools and people. Above all, the uniformity of the data could be probably compromised. Here is a series of conditions analysis and conflicting demands to be met:

- Extended surfaces to be covered with UAV photogrammetric approach require large flight plan or combination of blocks acquisitions, split at different times. Acquisitions time estimation is thus subjective to wideness and complexity, and drone engines however not support long time endurance

- Macro-topography (cliff, hills, slopes, etc.) require ad-hoc flight planning too, following the terrain trend a flight altitude that is as constant as possible; this again involves a reorganization of the flight strips coverage, with the consequences mentioned above.

- the accuracy assessment of the 3D mapping is conventionally conducted with control point distribution on the area with significant deployment of time for manual measures with GNSS receivers

- speeding up measurements time and chasing the limitation of the operator intervention means to improve research towards direct georeferencing solution of drone positioning on-the-flight, thanks to very accurate GNSS on-board sensor equipment and with Real Time Kinematic (RTK) or Post Processing Kinematic (PPK) techniques.

- the presence of structures that require the use of tilting cameras configuration, as high-oblique and low-oblique images, according to the verticality entity and strictly connected with the flight elevation. - however, the GSD planning is negatively influenced by the use of nadir and oblique images integration, unlike overlapping parameter, which instead is helped by the use of both camera setting.

- lowering the flight means guaranteeing a higher GSD but also increasing the acquisition times and probably cumulating the number of images blocks configuration

- the imaging sensors payloads performance (dimension, sensitivity, etc.) influence the image capturing quality, and typically it is inversely proportional to the economic factor

- splitting into separate flight blocks can cause the change of environmental light conditions; because of this, the final radiometric quality on 3D models-orthoimage can be compromised, if not with the consumption of semi-automatic images post-processing time - mostly as regards the light condition, depending on the type of site, surfaces materials and colours, and homogenous terrain textures may appear differently in the deferred images shooting, with changing shadows conditions, influencing the tie points extraction and the image-matching process

\section{CONCLUSION AND FUTURE PERSPECTIVES}

In the proposed research a couple of final consideration can be addressed both in the direction of the employed platform and in 
the fulfilment of the main 3D mapping goal in the Hierapolis site. Considering the procedure of direct photogrammetry approach with the use of the new eBee X platform, suitable metric result have been obtained for the expected result and scale (1:500 scale detail) of the entire DSM of the city, also with the contribution of oblique image point of view. These are the first tests and results in a challenging context and they need further analyzed in a controlled environment, but it is possible to say that the use of stand-alone PPK data retrieve good results, despite an increase of performance with use of a small set of GCPs. The topographic approach is still needed to reach high accuracy but reduced to a small set of well-distributed measured points. The general discussion linked to the upgrading of geometric content with the use of tilting camera from S.O.D.A 3D for the generation of complete and accurate 3D documentation demonstrate that the contribution of the oblique image is evident but still reduced by the flight altitude if it's too high. The effective improvement in $3 \mathrm{D}$ reconstruction mostly depends from controlled elevation of the flight and thus benefits from a larger convergence in the intersection of the projecting rays.

\section{ACKNOWLEDGEMENTS}

The authors would like to thank Prof. G. Semeraro director of the MAIER. A particular mention to the collaboration with C. Yildiz, N. A. Hararci and S. Ileri from APEKS Harita Mühendislik, Engineering service, Ankara (Turkey) for the flight acquisition cooperation and for supporting us to cope with unexpected events that typically happens in the fieldwork.

\section{REFERENCES}

Amrullah, C., Suwardhi, D., \& Meilano, I. (2016). Product accuracy effect of oblique and vertical non-metric digital camera utilization in UAV-photogrammetry to determine fault plane. ISPRS Annals of Photogrammetry, Remote Sensing and Spatial Information Sciences, III-6(July), 41-48. https://doi.org/10.5194/isprsannals-III-6-412016

Campana, S. (2017). Drones in Archaeology. State-of-the-art and Future Perspectives. Archaeological Prospection. https://doi.org/10.1002/arp.1569

Casella, V., \& Franzini, M. (2016). Modelling steep surfaces by various configurations of nadir and oblique photogrammetry. ISPRS Annals of Photogrammetry, Remote Sensing and Spatial Information Sciences, III-1(July), 175-182. https://doi.org/10.5194/isprsannalsIII-1-175-2016

Chiabrando, F., D’Andria, F., Sammartano, G., \& Spanò, A. (2018). UAV photogrammetry for archaeological site survey. 3D models at the Hierapolis in Phrygia (Turkey). Virtual Archaeology Review, 9(18), 28. https://doi.org/10.4995/var.2018.5958

Chiabrando, F., Giulio Tonolo, F., \& Lingua, A. (2019). UAV direct georeferencing approach in an emergency mapping context. The 2016 central Italy earthquake case study. International Archives of the Photogrammetry, Remote Sensing and Spatial Information Sciences - ISPRS Archives, 42(2/W13), 247-253. https://doi.org/10.5194/isprs-archives-XLII-2-W13-247-2019

Chiabrando, F., Spanò, A. T., Sammartano, G., \& Teppati Losè, L. (2017). UAV oblique photogrammetry and lidar data acquisition for 3D documentation of the Hercules Fountain. Virtual Archaeology Review, 8(16), 83. https://doi.org/10.4995/var.2017.5961

Colomina, I., \& Molina, P. (2014). Unmanned aerial systems for photogrammetry and remote sensing: A review. ISPRS Journal of Photogrammetry and Remote Sensing, 92, 79-97. https://doi.org/10.1016/j.isprsjprs.2014.02.013

D’Andria, F., Scardozzi, G., Spanò, A. (2008). Atlante di Hierapolis di Frigia. (Ege Yayinlari, Ed.). Istanbul.

Ekaso, D., Nex, F., \& Kerle, N. (2020). Accuracy assessment of real- time kinematics (RTK) measurements on unmanned aerial vehicles (UAV) for direct geo-referencing. Geo-Spatial Information Science, 1-17. https://doi.org/10.1080/10095020.2019.1710437

Guidi, G., Russo, M., Ercoli, S., Remondino, F., Rizzi, A., \& Menna, F. (2009). A Multi-Resolution Methodology for the 3D Modeling of Large and Complex Archeological Areas. International Journal of Architectural Computing, 7(1), 39-55. https://doi.org/10.1260/147807709788549439

Harwin, S., \& Lucieer, A. (2012). Assessing the Accuracy of Georeferenced Point Clouds Produced via Multi-View Stereopsis from Unmanned Aerial Vehicle (UAV) Imagery. Remote Sensing, 4(6), 1573-1599. https://doi.org/10.3390/rs4061573

Kraus, K., Jansa, J., \& Kager, H. (1997). Photogrammetry, Vol. 2 Advanced Methods and Applications. Dümmler/Bonn.

Lingua, A., Noardo, F., Spanò, A. T., Sanna, S., \& Matrone, F. (2017). 3D model generation using oblique images acquired by UAV. ISPRS - International Archives of the Photogrammetry, Remote Sensing and Spatial Information Sciences, XLII-4/W2, 107-115. https://doi.org/10.5194/isprs-archives-XLII-4-W2-107-2017

Meinen, B. U., \& Robinson, D. T. (2020). Mapping erosion and deposition in an agricultural landscape: Optimization of UAV image acquisition schemes for SfM-MVS. Remote Sensing of Environment, 239, 111666. https://doi.org/10.1016/j.rse.2020.111666

Murtiyoso, A., \& Grussenmeyer, P. (2017). Documentation of heritage buildings using close-range UAV images: dense matching issues, comparison and case studies. The Photogrammetric Record, 32(159), 206-229. https://doi.org/10.1111/phor.12197

Nesbit, P., \& Hugenholtz, C. (2019). Enhancing UAV-SfM 3D Model Accuracy in High-Relief Landscapes by Incorporating Oblique Images. Remote Sensing, 11(3), 239. https://doi.org/10.3390/rs11030239

Nex, F., \& Remondino, F. (2014). UAV for 3D mapping applications: a review. Applied Geomatics, 6(1), 1-15. https://doi.org/10.1007/s12518-013-0120-x

Nikolakopoulos, K. G., Soura, K., Koukouvelas, I. K., \& Argyropoulos, N. G. (2017). UAV vs classical aerial photogrammetry for archaeological studies. Journal of Archaeological Science: Reports, 14, 758-773. https://doi.org/10.1016/j.jasrep.2016.09.004

Remondino, F., Gruen, A., et al. (2009). Multi-sensor 3D documentation of the Maya site of Copan, (October), 131. https://doi.org/10.13140/2.1.2831.3929

Sauerbier, M., \& Eisenbeiß, H. (2010). UAVs for the documentation of archaeological excavations. ISPRS Archives, 38-5, 526-531.

Spanò, A., Chiabrando, F., Sammartano, G., \& Teppati Losè, L. (2018). Integrated imaging approaches supporting the excavation activities. multiscale geospatial documentation in Hierapolis (TK). ISPRS - International Archives of the Photogrammetry, Remote Sensing and Spatial Information Sciences, XLII-2(2), 1075-1082. https://doi.org/10.5194/isprs-archives-XLII-2-1075-2018

Teppati Losè, L. (2019). Geomatics support to the metric documentation of the archaeological heritage. Tests and validations on the use of low-cost, rapid, image-based sensors and systems. $\mathrm{PhD}$ Thesis, Prof. A. Spanò and Prof. F. Chiabrando supervisors. DAD Politecnico di Torino.

Themistocleous, K. (2014). The use of UAV platforms for remote sensing applications: case studies in Cyprus. In D. G. Hadjimitsis, K. Themistocleous, S. Michaelides, \& G. Papadavid (Eds.) (p. 92290S). https://doi.org/10.1117/12.2069514

Verykokou, S., \& Ioannidis, C. (2018). Oblique aerial images: a review focusing on georeferencing procedures. International Journal of Remote Sensing, 39(11), 3452-3496. https://doi.org/10.1080/01431161.2018.1444294 